\title{
Cervical sagittal parameters were closely related to Neck Disability Index score after anterior cervical decompression and fusion
}

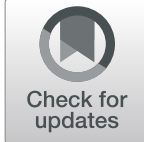

Yefu $\mathrm{Xu}^{1,2^{*}}$, Sangni Liu'2, Feng Wang ${ }^{1,2}$ and Xiaotao $\mathrm{Wu}^{1,2}$ (D)

\begin{abstract}
Background: ACDF treatment of CSM is currently recognized as a surgical method with reliable efficacy. However, the cervical radiographic findings in a certain group of patients showed that the symptoms were not completely relieved. This study will investigate the relationship between cervical parameters and prognoses after ACDF surgery.

Methods: This study collected cases of CSM treated with ACDF in Zhongda Hospital from May 2014 to June 2018. The investigators recorded gender, age, cervical sagittal parameters, fusion segment, BMI, symptom duration, and NDI score. To compare the changes of parameters after surgery and explore the correlation between each factor and NDI score.

Results: Generally, cervical lordosis increased and TS-CL decreased after surgery and during follow-up. Postoperative T1S, SVA and SCA decreased significantly compared to preoperative. T1S was positively correlated with CL $(r=0.245)$, SVA $(r=0.184)$, and negatively correlated with SCA $(r=-0.314)$ and NT $(r=-0.222)$. The last follow-up NDI score was positively correlated with T1S $(r=0.689)$, SVA $(r=0.155)$, TS-CL $(r=0.496)$, and age $(r=0.194)$, while negatively correlated with SCA $(r=-0.142)$. A linear regression model was established with the following formula: $\mathrm{NDI}=0.809 \times(\mathrm{T} 1 \mathrm{~S})-0.152 \times(\mathrm{CL})+1.962 \times(\mathrm{Sex})+0.110 \times(\mathrm{Age}) . \mathrm{T1S}(B=0.205, P<0.001), \mathrm{CL}$ $(B=-0.094, P=0.041)$, and NT $(B=0.142, P=0.023)$ were independent risk factors that affected whether the last follow-up NDI score was greater than preoperative.

Conclusions: In ACDF treatment of CSM, there exists a close correlation between cervical sagittal parameters and NDI scores. T1S, CL, sex, and age were linearly dependent on NDI scores. The increase of T1S, NT, and the decrease of $\mathrm{CL}$ were risk factors that affected follow-up NDI score greater than preoperative. Reducing T1S is beneficial to clinical recovery.
\end{abstract}

Keywords: Anterior cervical decompression and fusion (ACDF), Cervical spondylotic myelopathy (CSM), Cervical sagittal parameters

\footnotetext{
*Correspondence: xuyefu01@163.com

'Department of Spine Surgery, Zhongda Hospital, No. 87 Dingjiaqiao, Gulou District, Nanjing 210009, China

${ }^{2}$ School of Medicine, Southeast University, Nanjing 210009, China
}

(c) The Author(s). 2020 Open Access This article is licensed under a Creative Commons Attribution 4.0 International License, which permits use, sharing, adaptation, distribution and reproduction in any medium or format, as long as you give appropriate credit to the original author(s) and the source, provide a link to the Creative Commons licence, and indicate if changes were made. The images or other third party material in this article are included in the article's Creative Commons licence, unless indicated otherwise in a credit line to the material. If material is not included in the article's Creative Commons licence and your intended use is not permitted by statutory regulation or exceeds the permitted use, you will need to obtain permission directly from the copyright holder. To view a copy of this licence, visit http://creativecommons.org/licenses/by/4.0/. The Creative Commons Public Domain Dedication waiver (http://creativecommons.org/publicdomain/zero/1.0/) applies to the data made available in this article, unless otherwise stated in a credit line to the data. 


\section{Introduction}

The sagittal balance of the physiologically upright spine enables the intervertebral alignment to be maintained with minimal energy expenditure. Overloading of the cervical endplate can accelerate the degeneration of the spine, leading to cervical deformities that can lead to spinal cord compression and spinal cord tension [1]. Cervical spondylotic myelopathy (CSM) is one of the most common and harmful diseases in spine degenerative diseases, with the characteristics of concealment and intermittency. Anterior cervical decompression and fusion (ACDF) is an effective method for the treatment of cervical degenerative diseases.

ACDF can relieve symptoms by decompressing and releasing the spinal cord or nerve roots, which can effectively improve uncomfortable symptom. However, some patients still have postoperative symptoms of neck discomfort, sensation, and muscle strength decline. Researchers $[2,3]$ found that the patients with poor surgery effect, postoperative X-ray show up cervical lordosis (CL) loss, cervical sagittal vertical axial (cSVA), and thoracic 1 slope (T1S) oversize. They believed that cervical sagittal parameters were correlated with surgical outcomes and can affect prognostic.

NDI score is a common method to evaluate the surgical efficacy. Compared with other methods, NDI score is more comprehensive. It can reflect the recovery of neck function, the quality of patients' daily life, and the remission of pain. Although previous studies have found correlations between NDI score and CL, SVA and T1S, there were few studies that had explored the relationship between follow-up NDI score deterioration and cervical parameters. In this study, we analyzed linear regression between NDI and cervical parameters, and explore the risk factors of increased NDI score after surgery. We expect to find the cervical parameters that were valuable for evaluation of surgical prognosis.

\section{Materials and methods Subjects}

A retrospective study was conducted on cervical spondylotic myelopathy (CSM) patients treated with ACDF in spine surgery department of Zhongda Hospital from May 2014 to June 2018. Inclusion criteria and exclusion criteria are shown in Table 1. A total of 212 patients met the above criteria and were included in this study. Data were collected including gender, age, cervical sagittal parameters, fusion segment, body mass index (BMI), symptom duration, and NDI score.

\section{Measures}

Radiographic measurements

Lateral cervical X-ray examination: the patients maintain horizontal gaze with their neck in the center. Measurement parameters include $\mathrm{C} 2-7$ Cobb angle, C2-7 sagittal vertical axial (SVA), thoracic 1 slope (T1S), thoracic 1 slope minus cervical lordosis (TS$\mathrm{CL})$, thoracic inlet angle (TIA), neck tilt (NT), and spine-cranial angle (SCA). The measurement method of cervical parameters is shown in Figs. 1, 2 and 3 and Table 2. All parameters were measured twice independently by two surgeons. The two measurements are averaged and recorded. Imaging data collection was divided into three stages: preoperative (on admission), postoperative, and follow-up (last outpatient visit).

\section{Patient characteristics measures}

Gender, age, fusion segments, BMI, and symptom duration were collected through the hospital record system. NDI scores were collected at preoperative and the last follow-up. The patient voluntarily filled in the NDI scores scale, and the total score was calculated by researchers. The NDI score was used to evaluate neck function and surgical outcome

\section{Statistical analysis}

SPSS 21.0 (SPSS, Chicago) statistical software was used for statistical analysis of the measurement results. Descriptive analysis of preoperative, postoperative and follow-up parameters was conducted. Oneway ANOVA was used for comparison. Independent sample $t$ test was used to compare preoperative and follow-up NDI scores. Pearson analysis was used for inter-parameter correlation analysis and correlation between NDI scores and each factor. The linear regression equations of various factors and follow-up NDI scores were analyzed. $P$ value less than 0.05 has a statistically significant difference. Logistic analysis was conducted for all data and follow-up NDI score. Whether the last follow-up NDI score was greater

Table 1 Inclusion criteria and exclusion criteria

\begin{tabular}{|c|c|}
\hline Inclusion criteria & exclusion criteria \\
\hline $\begin{array}{l}\text { Typical signs and symptoms of } \\
\text { spinal cord compression, } \\
\text { combined with corresponding } \\
\text { MRI findings. }\end{array}$ & $\begin{array}{l}\text { previous history of cervical surgery, } \\
\text { clear history of trauma, spinal } \\
\text { tumor, infection, ankylosing } \\
\text { spondylitis, congenital deformity. }\end{array}$ \\
\hline $\begin{array}{l}\text { The patients treated with ACDF } \\
\text { in our hospital, with complete } \\
\text { data and clear anatomical } \\
\text { markers in X-ray image. }\end{array}$ & $\begin{array}{l}\text { incomplete clinical and imaging } \\
\text { data }\end{array}$ \\
\hline Follow-up time more than 1 year & $\begin{array}{l}\text { no imaging data of postoperative } \\
\text { follow-up. }\end{array}$ \\
\hline
\end{tabular}




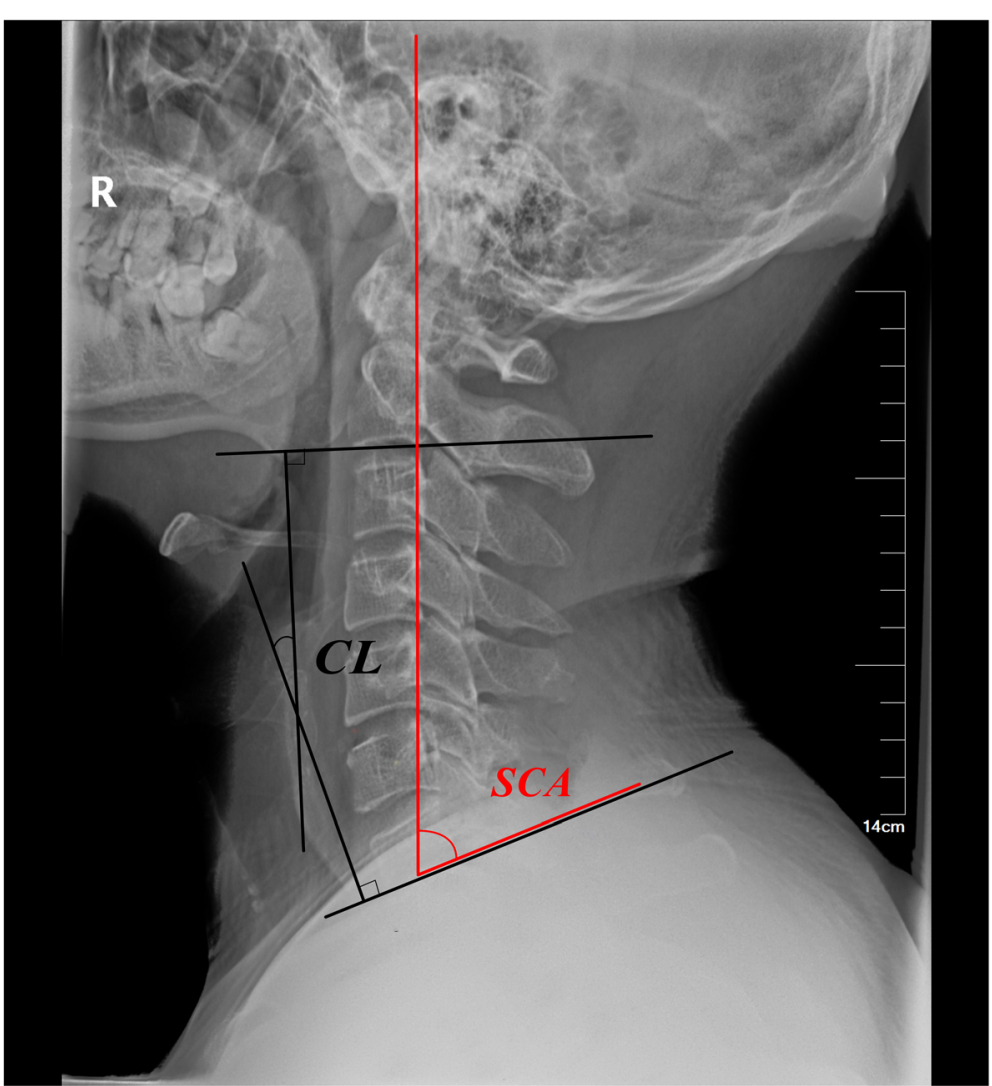

Fig. 1 Method for measuring C2-C7 lordosis, Spine-cranial angle

than preoperative was taken as the assessment result. All data were analyzed by binary logistic.

\section{Result}

\section{Clinical outcome}

In this study, a total of 212 patients were included that mean NDI score follow-up time were $14.72 \pm 5.93$ months. There were 147 male patients and 65 female patients, with an average age of $52.59 \pm 10.46$ years and an average BMI of $23.78 \pm 2.62 \mathrm{~kg} / \mathrm{m}^{2}$. Seventy-eight cases underwent single-segment $\mathrm{ACDF}$ and 134 cases underwent multi-segment ACDF. Amount of cases in operative segment was shown in Fig. 4. Duration of clinical symptoms was $9.38 \pm 16.95$ months. The preoperative NDI score was $20.84 \pm 6.17$, and the last follow-up NDI score was $16.52 \pm 6.90$, which was significantly lower than preoperative $(P<0.001)$, the difference was statistically significant.

\section{Changes of cervical sagittal parameters after surgery}

The cases were divided into single-segment group and multi-segment group for comparison of parameters and NDI scores. The result is shown in Table 3. In the comparison of all cases, cervical lordosis was increased immediately after surgery $(P=0.040)$ and at the last follow-up $(P<0.001)$ compared with preoperative. TS-CL was decreased after surgery $(P<0.001)$ and at the last follow-up $(P=0.001)$ compared with preoperative (Fig. 5). Postoperative T1S $(P<0.001)$, SVA $(P=0.042)$, and SCA $(P=0.004)$ decreased significantly compared with that before surgery, the difference was statistically significant. However, there were no significant differences in SCA $(P=0.965)$, T1S $(P=0.991)$, and SVA $(P=0.978)$ during follow-up compared with those before surgery. NT and TIA had no change after surgery and during follow-up.

In multi-segment group, postoperative $\operatorname{SVA}(P=0.015)$ and $\operatorname{T1S}(P<0.001)$ were smaller, and $\mathrm{SCA}(P<0.001)$ was larger than preoperative. However, in singlesegment group, there was no difference in postoperative T1S, SVA, and SCA compared with preoperative. Preoperative $\mathrm{NT}(P=0.006)$, postoperative $\mathrm{NT}(P=0.002)$, follow-up NT $(P=0.007)$, age $(P<0.001), \operatorname{sex}(P=0.014)$, and $\operatorname{BMI}(P=0.007)$ of multi-segment group have differences with single-segment group. 


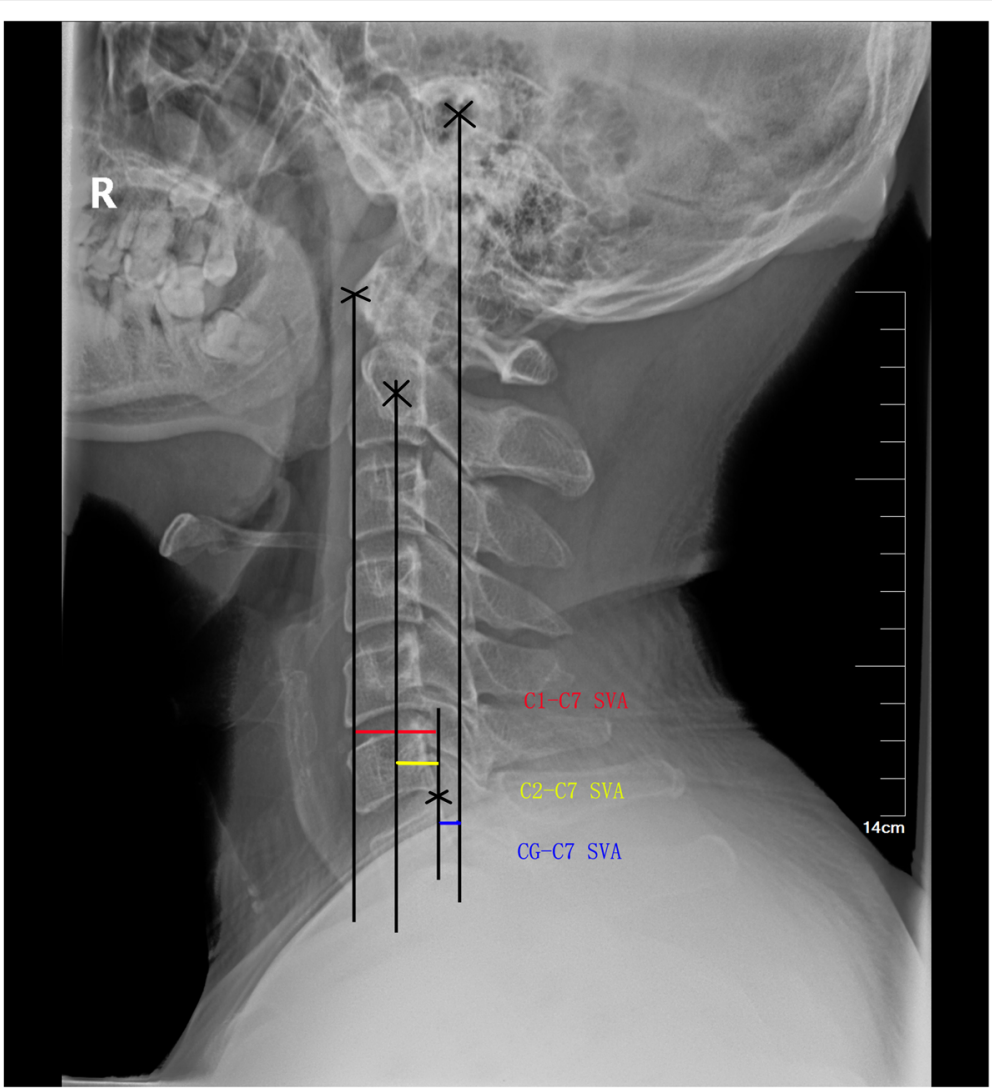

Fig. 2 Method for measuring C2-7 SVA, C1-7 SVA and CG-C7 SVA

\section{Correlation analysis of follow-up NDI scores, cervical sagittal parameters, and clinical data}

There was a close correlation between sagittal parameters at the last follow-up, as shown in Table 4. T1S was positively correlated with CL $(r=0.245)$, SVA $(r=$ $0.184)$, and negatively correlated with SCA $(r=-0.314)$ and NT $(r=-0.222)$. There was a significant correlation between SVA and TS-CL $(r=0.207)$, SVA and TIA $(r=$ $0.322)$, and SVA and SCA $(r=0.167)$. In addition, SCA is closely related to CL $(r=-0.573)$, and TIA is highly correlated to T1S + NT $(r=0.425, P<0.001)$.

The correlation analysis of follow-up NDI scores is shown in Table 4. NDI score was positively correlated with T1S $(r=0.689)$ (Fig. 6), SVA $(r=0.155)$, and TS-CL $(r=0.496)$ (as Fig. 7), while negatively correlated with SCA $(r=-0.142)$. There was no significant correlation between preoperative NDI score and CL, TIA, and NT. At the last follow-up, NDI score was positively correlated with age $(r=0.194)$, and no significant correlation with gender, BMI, singlesegment or multi-segment fusion, or duration of symptoms. Operative segment (single-segment ACDF or multi-segment ACDF) was associated with $\operatorname{SCA}(r=$
$0.147), \quad \mathrm{NT}(r=0.174), \quad \operatorname{sex}(r=-0.168), \operatorname{age}(r=$ $0.308)$, and $\operatorname{BMI}(r=0.184)$.

\section{Multiple regression analysis of NDI score}

According to the multiple regression and linear regression analysis of NDI score (Table 5$), \mathrm{T} 1 \mathrm{~S}(B=0.809$, $P<0.01), C L(B=-0.152, P=0.30)$, sex $(B=1.962, P=$ $0.016)$, and age $(B=0.110, P=0.06)$ were linearly dependent on NDI scores. A linear regression model was established with the following formula: NDI $=0.809$ $\times(\mathrm{T} 1 \mathrm{~S})-0.152 \times(\mathrm{CL})+1.962 \times(\mathrm{Sex})+0.110 \times($ Age $)$.

As shown in Table 6, 82 patients in group 1 were less than 50 years old. NDI score was correlated with $\mathrm{T} 1 \mathrm{~S}(r=0.658)$, TS-CL $(r=0.544)$, and SCA $(r=-0.303)$. In group 2,82 patients were aged $50-60$ years, and NDI score was correlated with $\mathrm{T} 1 \mathrm{~S}(r=0.581)$ and TS-CL $(r=0.436)$. Group 3 patients were over 60 years old, with a total of 48 patients. NDI score was correlated with $\mathrm{T} 1 \mathrm{~S}(r=0.717)$ and TS-CL $(r=0.363)$.

\section{Analysis of risk factors for last follow-up NDI score deterioration}

Whether the follow-up NDI score was higher than preoperative NDI was used as the dependent variable for 


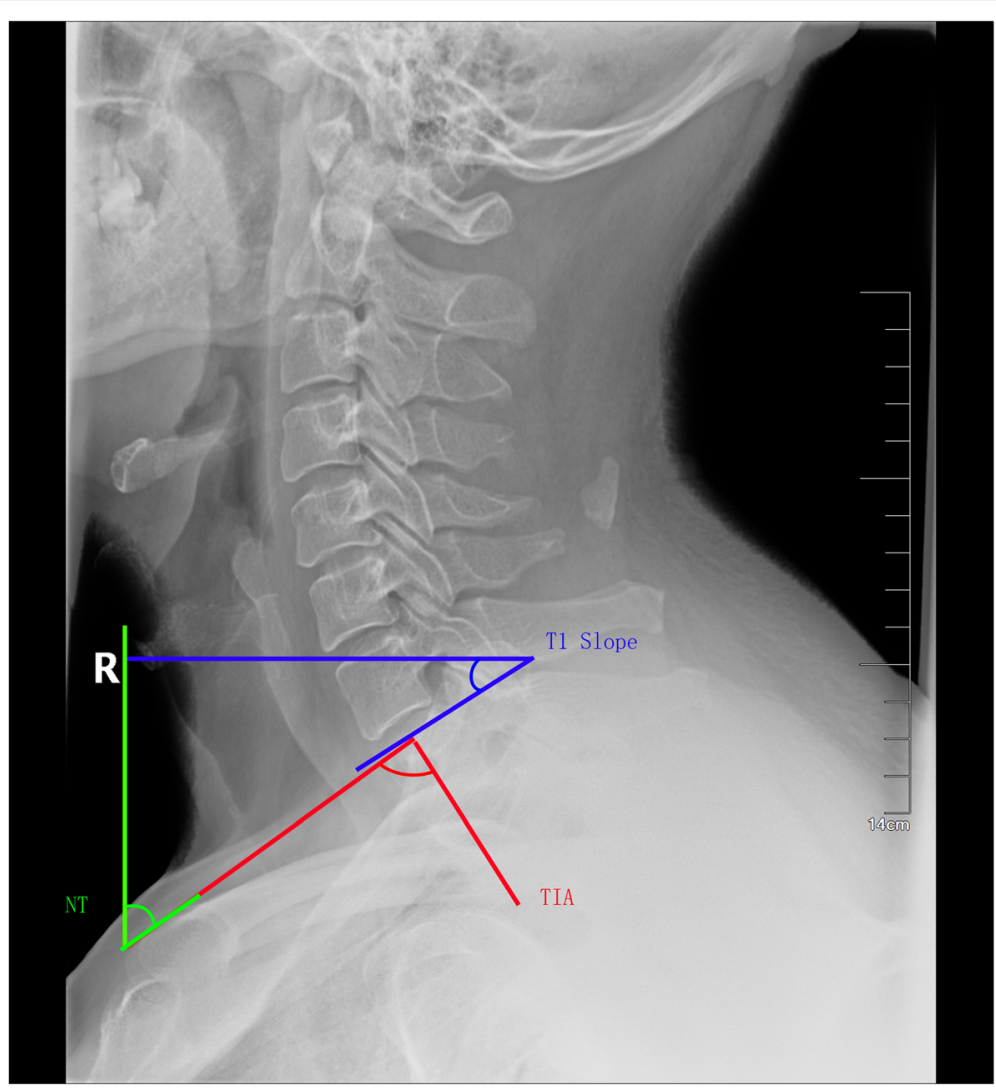

Fig. 3 Method for measuring T1S, NT and TIA

Table 2 measurement methods of each parameter

\begin{tabular}{|c|c|}
\hline & $\begin{array}{l}\text { Definition of all parameters used: parameters } \\
\text { description }\end{array}$ \\
\hline C2-C7 lordosis & $\begin{array}{l}\text { Angle between the lower plate of } \mathrm{C} 2 \text { and } \\
\text { the lower plate of } \mathrm{C} 7\end{array}$ \\
\hline C2-C7 SVA & $\begin{array}{l}\text { The distance from the posterior, superior } \\
\text { corner of } C 7 \text { to the plumb-line from the } \\
\text { centroid of } C 2\end{array}$ \\
\hline T1 slope & $\begin{array}{l}\text { Angle between a horizontal line and the } \\
\text { superior endplate of } \mathrm{T} 1\end{array}$ \\
\hline $\mathrm{TS}-\mathrm{CL}$ & Mismatch between $\mathrm{T} 1$ slope and $\mathrm{CL}$ \\
\hline Thoracic inlet angle & $\begin{array}{l}\text { Angle formed by a line perpendicular to } \\
\text { the superior endplate of } \mathrm{T} 1 \text { and a line } \\
\text { connecting the centre of } \\
\text { the } \mathrm{T} 1 \text { upper endplate and the upper } \\
\text { end of the sternum }\end{array}$ \\
\hline Neck tilt & $\begin{array}{l}\text { Angle formed by the reference vertical } \\
\text { line drawn in the upper end of the } \\
\text { sternum and a line connecting } \\
\text { the centre of the } T 1 \text { upper end plate } \\
\text { and the upper end of the sternum }\end{array}$ \\
\hline Spine-cranial angle & $\begin{array}{l}\text { The angle is defined between the } \\
\mathrm{C7} \text { slope and the straight line joining } \\
\text { the middle of the } \mathrm{C} 7 \text { end plate } \\
\text { and the middle of the sella turcica }\end{array}$ \\
\hline
\end{tabular}

logistics regression. The final result is shown in Table 7. TS-CL was strongly correlated with T1S and CL, so it was not included in the analysis. T1S $(B=0.205, P<$ $0.001), C L(B=-0.094, P=0.041)$ and NT $(B=0.142$, $P=0.023)$ were independent risk factors that affected whether the last follow-up NDI score was greater than preoperative.

\section{Reliability analysis}

The assessment of intra-observer and inter-observer reliability for cervical and thoracic parameters showed excellent consistency, respectively (Table 8).

\section{Discussion}

This study found that CL, SVA, T1S, and TS-CL were significantly improved after ACDF, while NT and TIA were relatively stable and not affected by ACDF, which was basically consistent with previous studies [4-6]; SCA, as a new parameter, increases in the postoperative measurement, while follow-up SCA is basically the same as preoperative, with no significant change. In addition, we also found that at the last follow-up, some parameters which improved significantly after surgery gradually changed to preoperative state, or even worse than preoperative. SVA and T1S 


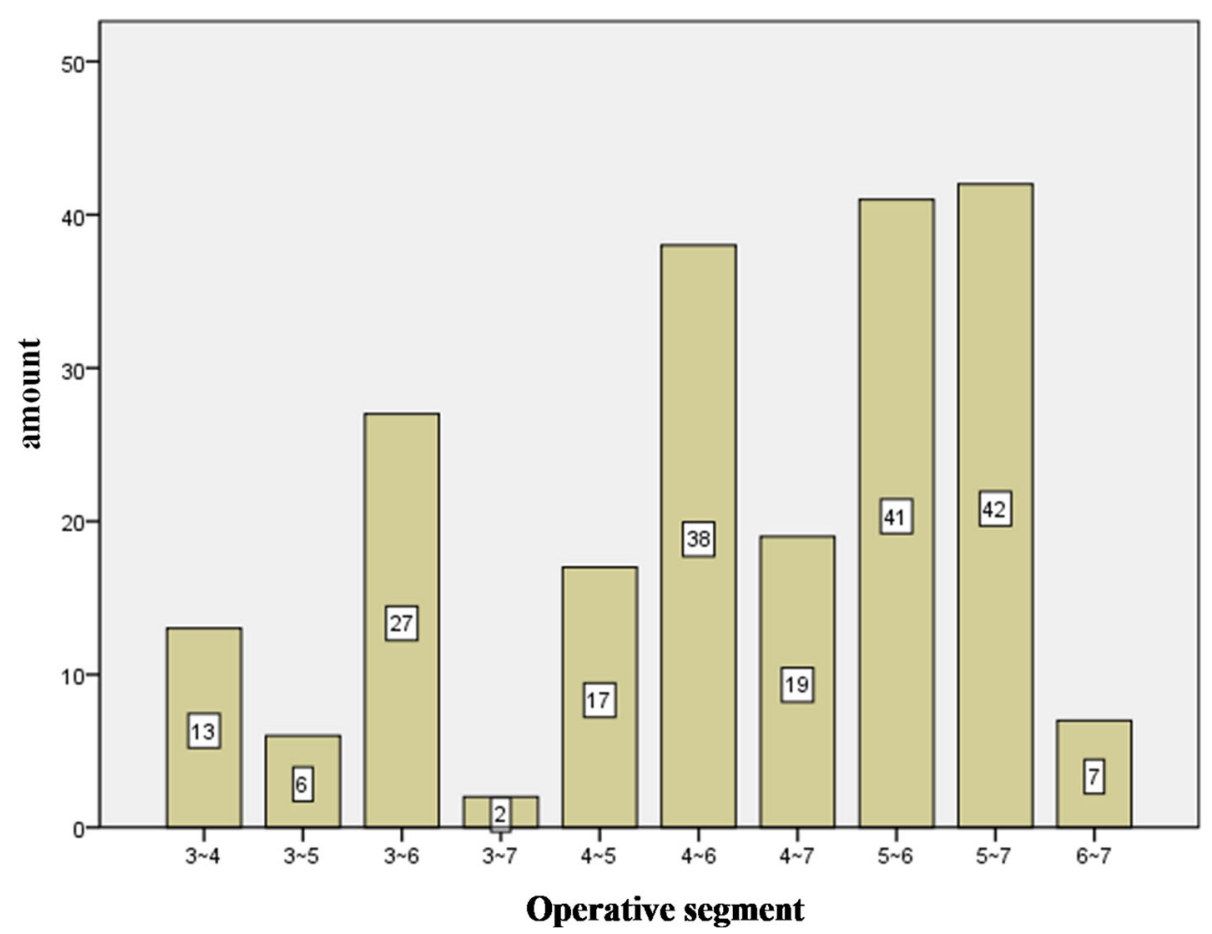

Fig. 4 Amount of cases in operative segment

improved significantly after surgery, but the orthopedic effect was lost at the last follow-up, which was close to preoperative level. It may be related to the changes in bearing weight and angle of adjacent segments, especially the lower cervical, after ACDF [7]; after fusion, the lower cervical and the intervertebral disc bear more weight, and due to orthopedic changes in the distribution of bearing angle and force, there are compensatory changes in the lower cervical, resulting in an increase in T1S compared with the preoperative level. In addition, we found that T1S, SVA, and SCA improved obviously after surgery in multi-segment group, while single-segment group showed no obvious improvement. Multi-segment ACDF can better improve cervical parameters and restore cervical sagittal balance. However, after multisegment ACDF, cervical stability is poorer and the adjacent stage disease (ASD) incidence is higher than single segment ACDF.

As for the evaluation of postoperative ACDF efficacy, commonly used methods include pain-related VAS score, cervical JOA score, and cervical NDI score. Studies have compared the efficacy of each scoring method in evaluating the efficacy of cervical orthopedic surgery [8]. Accordingly, cervical NDI score was used to evaluate postoperative spinal cord improvement and patients' quality of life. Because of the long recovery period of CSM, we used the last follow-up NDI scores to compare with that before surgery. After ACDF, NDI score was significantly improved compared with those of preoperative, but some patient follow-up NDI scores increase compared to preoperative NDI. In our study, whether the NDI score increased after surgery was used as dependent variables, and cervical parameters was used as independent variables, performing a binary logistic regression analysis.

The thoracic 1 vertebra is the bridge between cervical and thoracic vertebra. T1S is a very important parameter of cervical segment, which is closely related to other parameters as a bond [9]. T1S is not only closely correlated with CL and SVA, but also with NT. In addition, it is negatively correlated with SCA. Changes in T1S may reflect changes in the sagittal balance of cervicothoracic spine. Studies found that [10] there is a strong correlation between T1S and other parameters, and T1S changes earlier when cervical balance is destroyed. The majority of cervical imbalance is caused by disc herniation, neck muscle fatigue, surrounding ligament relaxation, and the dislocation of vertebral body alignment caused by longterm bending. These reasons may also lead to the increase of SVA and the decrease of CL. Studies [11] have found a significant negative correlation between 
Table 3 Comparison of cervical parameters between single-segment group and multi-segment group

\begin{tabular}{|c|c|c|c|c|c|}
\hline & & Total $(n=212)$ & Single-segment $(n=78)$ & Multi-segment $(n=134)$ & $P$ \\
\hline & Preoperative & $11.17 \pm 8.56$ & $11.69 \pm 8.51$ & $12.42 \pm 8.55$ & .552 \\
\hline & Postoperative & $13.30 \pm 7.53$ & $14.15 \pm 8.04$ & $13.56 \pm 7.21$ & .583 \\
\hline \multirow[t]{5}{*}{$\mathrm{CL}$} & Follow-up & $14.64 \pm 6.44$ & $15.33 \pm 6.42$ & $15.01 \pm 6.46$ & .738 \\
\hline & $P$ & 0.040 & .183 & .557 & \\
\hline & $P^{\prime}$ & $<0.001$ & .009 & .016 & \\
\hline & Preoperative & $15.64 \pm 9.12$ & $15.22 \pm 10.25$ & $15.88 \pm 8.42$ & 616 \\
\hline & Postoperative & $13.49 \pm 7.09$ & $13.80 \pm 8.47$ & $13.31 \pm 6.18$ & .632 \\
\hline \multirow[t]{5}{*}{ SVA } & Follow-up & $16.23 \pm 7.72$ & $15.99 \pm 9.06$ & $15.79 \pm 6.82$ & .277 \\
\hline & $P$ & 0.042 & 0.718 & .015 & \\
\hline & $P^{\prime}$ & 0.978 & 0.588 & .999 & \\
\hline & Preoperative & $20.11 \pm 6.08$ & $20.08 \pm 5.83$ & $20.13 \pm 6.25$ & .954 \\
\hline & Postoperative & $17.48 \pm 5.96$ & $18.36 \pm 6.13$ & $16.97 \pm 5.82$ & .103 \\
\hline \multirow[t]{5}{*}{ T1S } & Follow-up & $20.26 \pm 6.04$ & $20.00 \pm 5.41$ & $20.42 \pm 6.39$ & .623 \\
\hline & $\mathrm{P}$ & $<0.001$ & .206 & $<0.001$ & \\
\hline & $P^{\prime}$ & 0.991 & .999 & .975 & \\
\hline & Preoperative & $7.96 \pm 8.09$ & $8.39 \pm 8.85$ & $7.71 \pm 7.64$ & .556 \\
\hline & Postoperative & $3.70 \pm 6.87$ & $4.21 \pm 9.02$ & $3.41 \pm 5.25$ & .418 \\
\hline \multirow[t]{5}{*}{ TS-CL } & Follow-up & $5.14 \pm 7.67$ & $4.67 \pm 7.03$ & $5.41 \pm 8.03$ & .502 \\
\hline & $P$ & 0.001 & .012 & $<0.001$ & \\
\hline & $P^{\prime}$ & 0.001 & .013 & .050 & \\
\hline & Preoperative & $76.33 \pm 8.07$ & $76.89 \pm 8.83$ & $76.78 \pm 7.63$ & .923 \\
\hline & Postoperative & $78.67 \pm 5.72$ & $79.13 \pm 5.38$ & $79.20 \pm 5.95$ & .924 \\
\hline \multirow[t]{5}{*}{ SCA } & Follow-up & $75.75 \pm 6.74$ & $74.98 \pm 7.02$ & $77.04 \pm 6.53$ & .033 \\
\hline & $P$ & 0.004 & .164 & .012 & \\
\hline & $P^{\prime}$ & 0.965 & .358 & .986 & \\
\hline & Preoperative & $57.91 \pm 5.56$ & $57.09 \pm 5.08$ & $59.23 \pm 5.71$ & .006 \\
\hline & Postoperative & $57.16 \pm 5.40$ & $56.16 \pm 4.63$ & $58.57 \pm 5.67$ & .002 \\
\hline \multirow[t]{5}{*}{ NT } & Follow-up & $56.87 \pm 5.18$ & $56.11 \pm 4.33$ & $58.11 \pm 5.55$ & .007 \\
\hline & $P$ & 0.639 & .546 & .711 & \\
\hline & $P^{\prime}$ & 0.252 & .477 & .280 & \\
\hline & Preoperative & $78.59 \pm 7.25$ & $78.00 \pm 7.59$ & $79.73 \pm 7.03$ & .095 \\
\hline & Postoperative & $77.50 \pm 6.52$ & $75.78 \pm 5.39$ & $79.26 \pm 6.80$ & $<0.001$ \\
\hline \multirow[t]{4}{*}{ TIA } & Follow-up & $78.95 \pm 6.62$ & $78.78 \pm 5.51$ & $79.86 \pm 7.21$ & .257 \\
\hline & P & 0.483 & .106 & .924 & \\
\hline & $P^{\prime}$ & 0.996 & .846 & .998 & \\
\hline & Preoperative & $20.84 \pm 6.17$ & $20.92 \pm 5.87$ & $20.79 \pm 6.35$ & .881 \\
\hline \multirow[t]{2}{*}{ NDI score } & Follow-up & $16.52 \pm 6.90$ & $16.29 \pm 6.36$ & $16.66 \pm 7.20$ & .714 \\
\hline & $p$ & $<0.001$ & $<0.001$ & $<0.001$ & \\
\hline $\mathrm{BMI}\left(\mathrm{Kg} / \mathrm{m}^{2}\right)$ & & $23.78 \pm 2.62$ & $23.15 \pm 2.43$ & $24.15 \pm 2.67$ & .007 \\
\hline Sex (male/female) & & $147 / 65$ & $62 / 16$ & $85 / 49$ & .014 \\
\hline Age (years) & & $52.59 \pm 10.46$ & $48.38 \pm 10.12$ & $55.04 \pm 9.88$ & .000 \\
\hline Duration of symptoms (mouths) & & $9.38 \pm 16.95$ & $9.04 \pm 18.28$ & $9.58 \pm 16.19$ & .824 \\
\hline
\end{tabular}

Comparisons of preoperative, postoperative and follow-up cervical parameters, $P$ was result of preoperative and postoperative comparison, $P^{\prime}$ was result of preoperative and follow-up comparison 


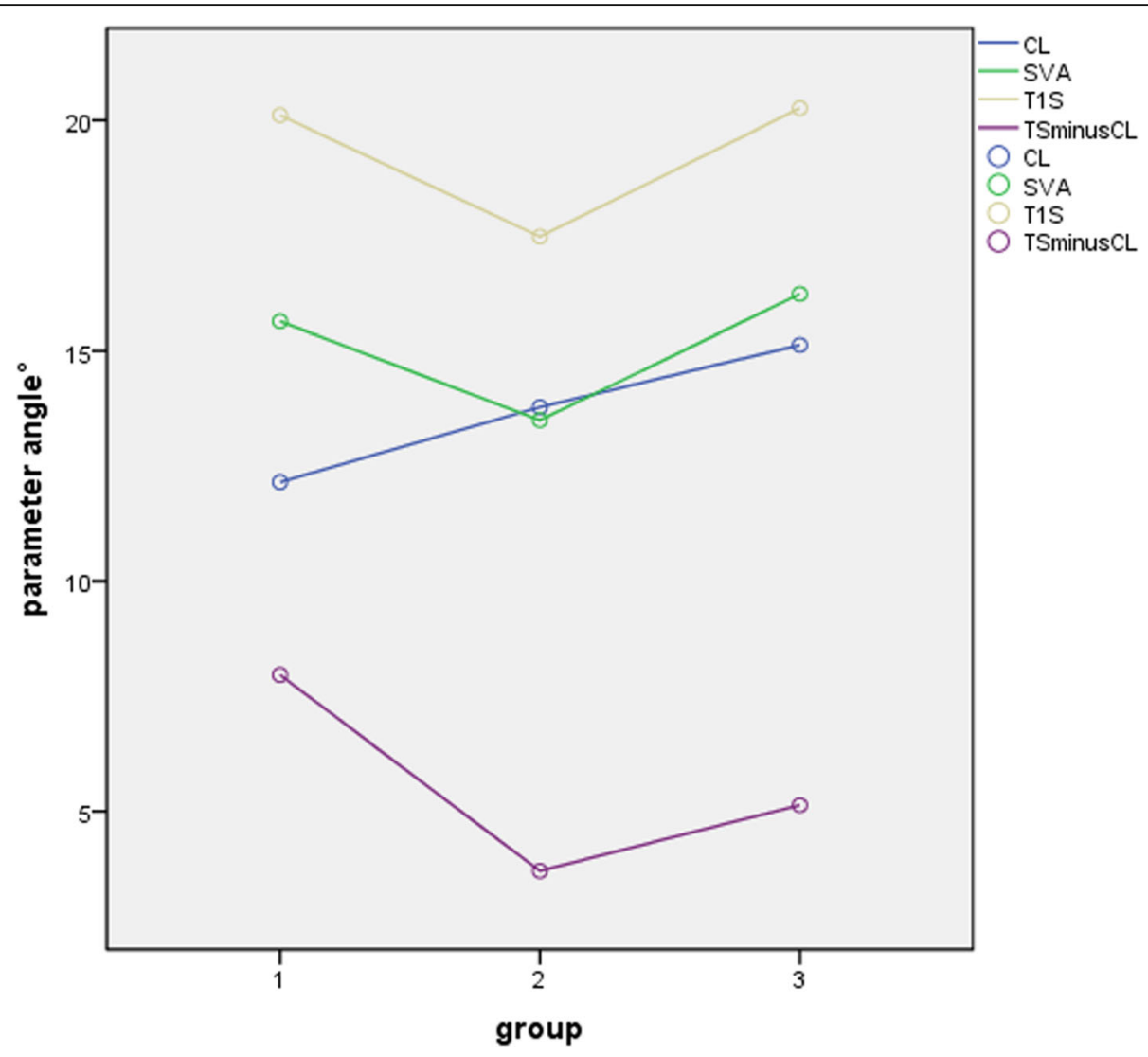

Fig. 5 The changes of radiographic parameters after ACDF

C2-7 Cobb angle and cervical SVA. In asymptomatic Chinese population, CL was significantly correlated with other cervical sagittal parameters including TIA, T1S, NT, and C2-7 SVA [12].
SCA, a new parameter introduced in recent years, is mainly used to reflect the balance of the head and neck spine. SCA has a high correlation with T1S and $\mathrm{CL}$, and a weak correlation with SVA, which is the link between cervical segment and cranium. It was found

Table 4 Correlation Between Radiographic Parameters and NDI Scores at the last follow-up

\begin{tabular}{|c|c|c|c|c|c|c|c|c|c|c|c|c|c|}
\hline & $\mathrm{CL}$ & T1S & SVA & TS-CL & SCA & NT & TIA & $\mathrm{NDI}$ & Age & Sex & BMI & Time & Segment \\
\hline$\overline{\mathrm{CL}}$ & $x$ & $.245^{* * *}$ & -.074 & $-.646^{* *}$ & $-.573^{* * *}$ & $-.227^{* *}$ & $.200^{* * *}$ & .055 & .064 & -.014 & -.027 & .080 & -.023 \\
\hline T1S & & $x$ & $.184^{* *}$ & $.582^{* *}$ & $-.314^{* *}$ & $-.222^{* *}$ & .098 & $.689^{* *}$ & .128 & -.009 & -.007 & .004 & .034 \\
\hline CSVA & & & $x$ & $.207^{* *}$ & $.167^{*}$ & -.053 & $.322^{* * *}$ & $.155^{*}$ & $.150^{*}$ & $.283^{* *}$ & $.279^{* *}$ & -.132 & -.075 \\
\hline TS-CL & & & & $x$ & $.234^{* *}$ & .015 & -.090 & $.496^{* *}$ & .047 & .005 & .018 & -.063 & .046 \\
\hline SCA & & & & & $x$ & $.349^{* *}$ & -.134 & $-.142^{*}$ & $.327^{* *}$ & .107 & $.200^{* *}$ & -.016 & $.147^{*}$ \\
\hline NT & & & & & & $x$ & $.461^{* *}$ & -.072 & $.156^{*}$ & -.073 & $.207^{* *}$ & .023 & $.174^{*}$ \\
\hline TIA & & & & & & & $x$ & .047 & .132 & -.086 & $.291^{* *}$ & .037 & .078 \\
\hline NDI & & & & & & & & $x$ & $.194^{* *}$ & .095 & -.004 & -.029 & .025 \\
\hline Age & & & & & & & & & $x$ & -.120 & $.158^{*}$ & .123 & $.308^{* *}$ \\
\hline Sex & & & & & & & & & & $x$ & .124 & -.078 & $-.168^{*}$ \\
\hline BMI & & & & & & & & & & & $x$ & -.111 & $.184^{* *}$ \\
\hline Time & & & & & & & & & & & & $x$ & .015 \\
\hline Segment & & & & & & & & & & & & & $x$ \\
\hline
\end{tabular}

**Correlation is significant at the 0.01 level (2 tailed); ${ }^{*}$ Correlation is significant at the 0.05 level ( 2 tailed)

Time indicates duration of symptoms; Segment: single-segment indicates 0; multiple-segment indicates 1 


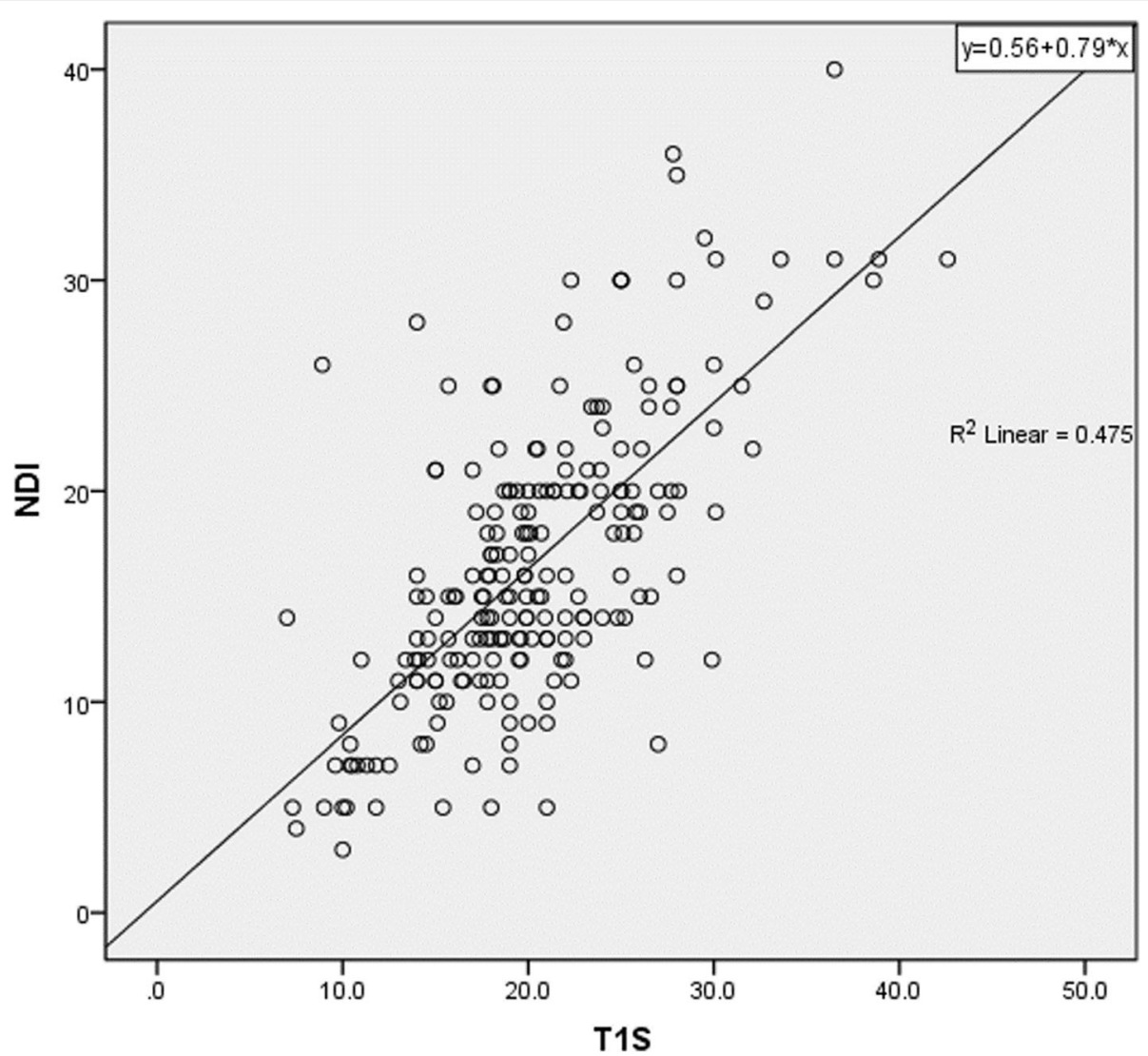

Fig. 6 A positive correlation was observed between NDI scores and T1S values

in previous studies [13] that TIA was approximately equal to the sum of T1S plus NT, which was also confirmed in this study. TIA and NT were not sensitive to surgical changes, and the postoperative changes of T1S were relatively large. However, this equation was valid both before and after surgery. When T1S changes significantly, TIA and NT make corresponding adjustments to adapt. This allows the balance of the upper spine to be maintained with minimal changes.

Studies [2, 14] found a correlation between NDI score and cervical parameters. Preoperative NDI score increased with the increase of C2-7 SVA and TS-CL, while high C2-7 SVA and low TIA were independent predictors of high preoperative NDI score. Preoperative T1S was positively correlated with preoperative NDI score, and postoperative follow-up T1S was positively correlated with follow-up NDI score. In addition, C2-7 SVA, and TS-CL were positively correlated with NDI score respectively. It can be considered that cervical sagittal parameters are closely related to NDI score. Cervical parameters can be used to evaluate the prognosis of patients after ACDF. Oversize T1S, SVA, and mismatched TS-CL will have adverse effects on the prognosis. This study also found a negative correlation between NDI score and SCA. SCA is an important parameter for maintaining sagittal balance of cervical spine and maintaining a normal value of $83^{\circ} \pm$ $9^{\circ}$ can promote good prognosis [15].

It is believed that cervical curvature has an impact on surgical prognosis, and the improvement of cervical lordosis will affect the long-term efficacy of ACDF in the treatment of degenerative cervical disc disease [16]. Kyphosis of the cervical can affect the outcome of surgery. Cervical kyphosis is associated with increased neck pain before and after cervical surgery [17]. In this study, decreased cervical lordosis was a risk factor for deterioration of the last followup NDI score. Existing researches suggest that [18] patients with kyphosis are 18 times more likely to have cervical symptoms, a risk factor for neck pain. In addition, kyphosis may become a risk factor for spinal cord compression after cervical orthopedic surgery. Maintaining or reconstructing cervical kyphosis after ACDF surgery is helpful to obtain a good prognosis, and correcting kyphosis deformity as far as possible is still an accepted surgical option.

This study found that excessive T1S and NT were risk factors for follow-up NDI score greater than 


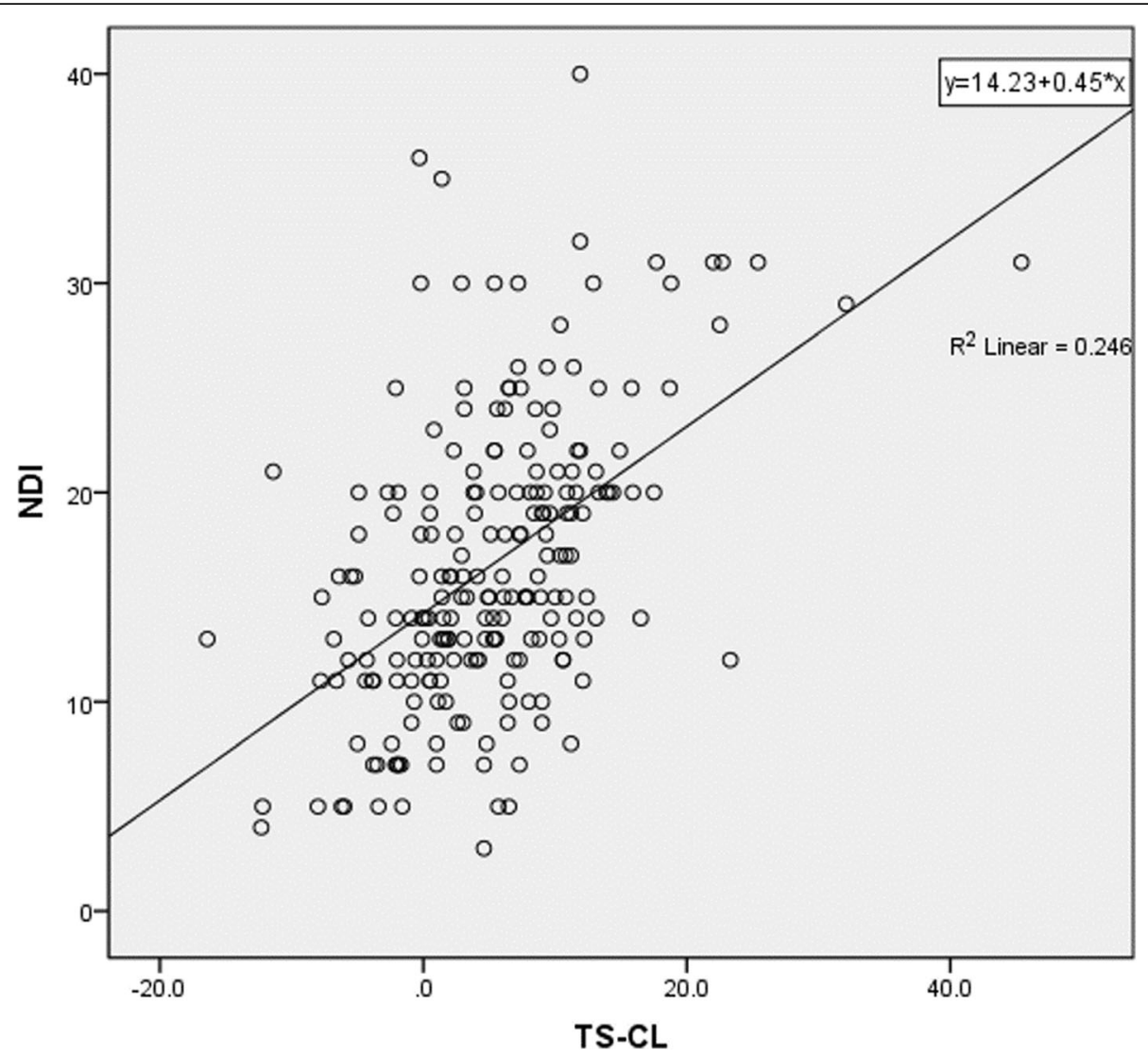

Fig. 7 A positive correlation was observed between NDI scores and TS-CL values

preoperative, which may lead to poor prognosis. Studies [3] have found that there is a linear relationship between T1S and postoperative NDI score. When T1S $>40^{\circ}$ will lead to poor prognosis, T1S can be used as a parameter to evaluate prognosis. In addition, increased SVA will

Table 5 Multiple regression analysis and linear regression of NDI score

\begin{tabular}{llll}
\hline & B & Standardized Coefficients & Sig \\
\hline T1S & 0.809 & 0.707 & .000 \\
SVA & -0.011 & -0.012 & .847 \\
SCA & -0.084 & -0.082 & .288 \\
CL & -0.152 & -0.142 & .030 \\
NT & 0.130 & 0.098 & .159 \\
TIA & -0.046 & -0.044 & .541 \\
Age & 0.110 & 0.166 & .006 \\
Sex & 1.962 & 0.131 & .016 \\
Single or multiple segments & -0.402 & -0.028 & .598 \\
Duration of symptoms & -0.015 & -0.038 & .455 \\
Constant & 0.511 & & .947 \\
\hline Sex:mat indicates 1; female indicates 0 & &
\end{tabular}

Sex: male indicates 1; female indicates 0

Single-segment indicates 0 ; multiple-segment indicates 1 also affect the surgical effect [19]. The increase of T1S is often accompanied by the deterioration of SVA. If they change together, a poor prognosis will be the result. In addition to the consideration of contact with spinal cord compression and decompression, the correction of cervical imbalance and the prevention of T1S gradual deterioration after surgery are also factors to be considered. T1S is highly correlated with other parameters and tends to deteriorate after surgery, which will

Table 6 Correlation analysis of follow-up cervical parameters and NDI score by age group

\begin{tabular}{|c|c|c|c|c|c|c|}
\hline & \multicolumn{2}{|c|}{ Group1 } & \multicolumn{2}{|c|}{ Group2 } & \multicolumn{2}{|c|}{ Group3 } \\
\hline & $r$ & $p$ & $r$ & $p$ & $r$ & $p$ \\
\hline C2-7 Cobb angle & 0.053 & 0.635 & 0.166 & 0.137 & 0.128 & 0.385 \\
\hline T1S & 0.658 & $<0.001$ & 0.581 & $<0.001$ & 0.717 & $<0.001$ \\
\hline CSVA & 0.015 & 0.890 & 0.187 & 0.093 & 0.120 & 0.416 \\
\hline TS-CL & 0.544 & $<0.001$ & 0.436 & $<0.001$ & 0.363 & 0.011 \\
\hline SCA & -0.303 & 0.006 & -0.211 & 0.057 & -0.195 & 0.184 \\
\hline NT & -0.029 & 0.793 & -0.022 & 0.843 & 0.016 & 0.912 \\
\hline TIA & 0.152 & 0.173 & 0.031 & 0.781 & -0.078 & 0.600 \\
\hline
\end{tabular}

Group1: age $<49$ years, Group2: age 50-60 years, Group3: age $>60$ years 
Table 7 risk factors analysis of NDI score worsen at the last follow-up

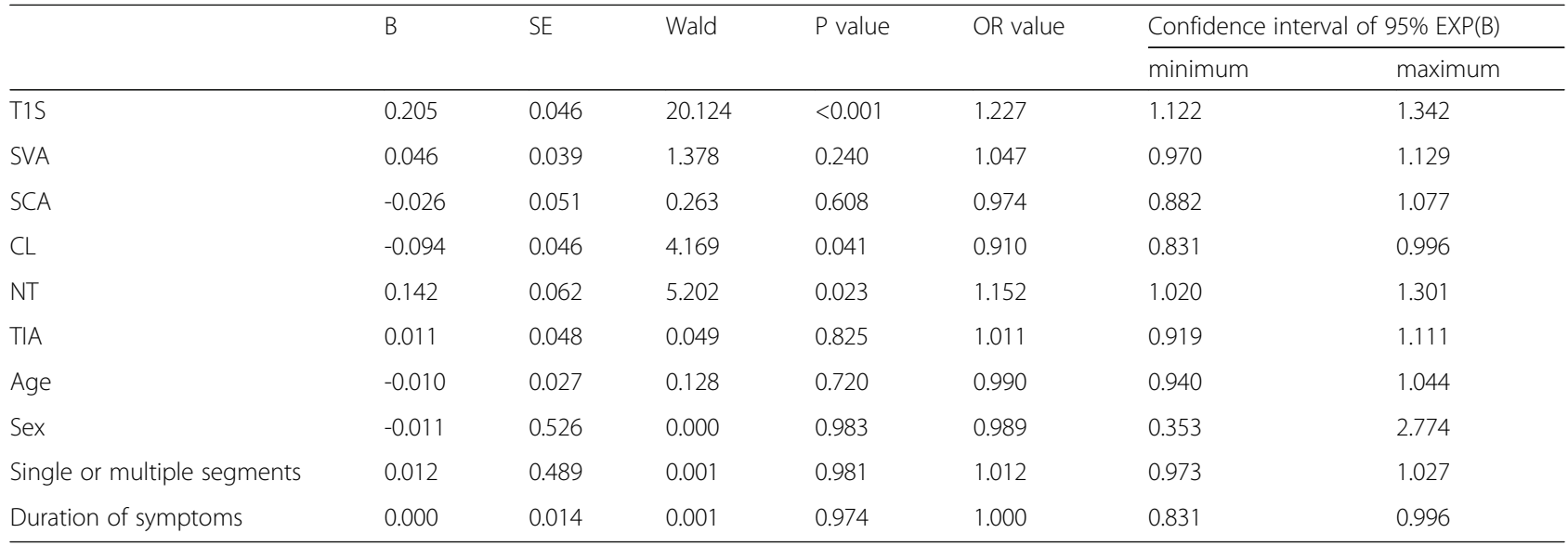

Sex: male indicates 1; female indicates 0

Single-segment indicates 0; multiple-segment indicates 1

lead to poor prognosis. Therefore, more attention should be paid to this parameter in the future.

Our study found that T1S is positively correlated with CL. Excessive T1S leads to the compensatory increase of $\mathrm{CL}$, which can maintain the horizontal gaze and relieve symptoms. However, due to cervical imbalance, intervertebral disc degeneration, hyperosteogeny, and muscle weakness, some cases did not have compensatory changes. Their postoperative T1S increased, but CL did not increase or even decreased. The result was an increase in follow-up NDI score.

Advanced age is associated with increased NDI score, which may relate to a number of reasons. It was found that $\mathrm{C} 0-7$ cervical lordosis, $\mathrm{C} 2-7$ cervical lordosis, and T1S were associated with age change [20]. In the elderly patients, cervical degeneration is severe and re-imbalance is likely to occur after surgery, leading to poor prognosis. The recovery rate of spinal cord in elderly patients is slower than that in middle-aged patients, and the clinical symptoms caused by long-term compression are not easy to recover, which affects the postoperative quality of life of

Table 8 Inter-observer Reliability and Intra-observer Reproducibility Using the Intraclass Correlation Coefficient*

\begin{tabular}{lll}
\hline & Inter-observer & Intra-observer \\
\hline T1S & 0.87 & 0.81 \\
CL & 0.79 & 0.72 \\
SVA & 0.88 & 0.82 \\
SCA & 0.90 & 0.86 \\
TS-CL & 0.86 & 0.83 \\
NT & 0.85 & 0.76 \\
TIA & 0.82 & 0.79 \\
\hline
\end{tabular}

*An intraclass correlation coefficient value of $<0.6$ indicates poor reliability; 0.60.79 indicates good reliability; and $0.8-1.0$ indicates excellent reliability patients. In this study, the correlation analysis of cervical parameters and NDI score was conducted in group according to age. We found that, compared with other two groups, the correlation between T1S and NDI score was stronger in the eldest group, and the correlation coefficient between other parameters and NDI score was smaller. In elderly patients, increased T1S is more likely to lead to increased NDI. However, they lack the compensatory ability for increased T1S.

\section{Conclusion}

ACDF treatment of CSM, there was closely correlation between cervical sagittal parameters and NDI scores. T1S, CL, sex, and age were linearly dependent on NDI scores. The increase of T1S, NT, and the decrease of CL were independent risk factors that affected follow-up NDI score greater than preoperative. Cervical sagittal parameters were important in assessing the prognosis of ACDF. Reducing T1S is beneficial to clinical recovery.

\section{Abbreviations}

ACDF: Anterior cervical decompression and fusion; CSM: Cervical spondylotic myelopathy; CL: Cervical lordosis; T1S: Thoracic 1 slope; SVA: Sagittal vertical axial; TS-CL: Thoracic 1 slope minus cervical lordosis; SCA: Spine-cranial angle; TIA: Thoracic inlet angle; NT: Neck tilt; NDI score: Neck Disability Index score; BMI: Body mass index; HRQOL: Health-related quality of life

\section{Acknowledgements \\ Not applicable}

\section{Authors' contributions}

YFX conceived and designed the study. YFX and SNL collected the data. YFX, SNL, and FW analyzed and interpreted the patient data. YFX and SNL wrote the paper. All authors read and approved the final manuscript. All authors have read the journal policies and have no issues relating to journal policies. All authors have seen the manuscript and approved to submit to your journal. The work described has not been submitted elsewhere for publication, in whole or in part. 


\section{Funding}

Funding received came from National Natural Science Foundation of China (project approval number: 81871810). The funders had no role in study design, data collection and analysis, decision to publish, and preparation of the manuscript.

\section{Availability of data and materials}

The data and materials have been uploaded to database as Supplementary Material.

\section{Ethics approval and consent to participate}

This article does not contain any studies with human participants or animals performed by any of the authors.

\section{Consent for publication}

Written informed consent for publication was obtained from all participants.

\section{Competing interests}

The authors declare that they have no competing interests.

Received: 19 March 2020 Accepted: 29 July 2020

Published online: 14 August 2020

\section{References}

1. Dudli S, Fields AJ, Samartzis D, Karppinen J, Lotz JC. Pathobiology of modic changes. Eur Spine J. 2016;25(11):3723-34. https://doi.org/10.1007/s00586016-4459-7.

2. Huang Y, Lan Z, Xu W. Analysis of sagittal alignment parameters following anterior cervical hybrid decompression and fusion of multilevel cervical Spondylotic myelopathy [J]. BMC Musculoskelet Disord. 2019;20:1.

3. Oe S, Yamato Y, Togawa D, et al. Preoperative T1 Slope More Than $40^{\circ}$ as a Risk Factor of Correction Loss in Patients With Adult Spinal Deformity[J]. Spine. 2016;41(19):E1168.

4. Scheer Justin K, Tang Jessica A, Smith Justin S, et al. Cervical spine alignment, sagittal deformity, and clinical implications: a review [J]. J Neurosurg Spine. 2013;19:141-59.

5. Soo PM, Kelly MP, Lee D-H, Woo-Kie M, Rahman R'KK, Daniel RK. Sagittal alignment as a predictor of clinical adjacent segment pathology requiring surgery after anterior cervical arthrodesis. Spine J. 2014;14(7):1228-34. https://doi.org/10.1016/j.spinee.2013.09.043.

6. Gillis CC, Kaszuba MC, Traynelis VC. Cervical radiographic parameters in 1and 2-level anterior cervical discectomy and fusion. J Neurosurg Spine. 2016;25(4):421-9. https://doi.org/10.3171/2016.2.SPINE151056.

7. Li J, Li Y, Kong F, Zhang D, Zhang Y, Shen Y. Adjacent segment degeneration after single-level anterior cervical decompression and fusion: disc space distraction and its impact on clinical outcomes. J Clin Neurosci. 2015;22:566-9.

8. Carreon LY, Glassman SD, Campbell MJ, Anderson PA. Neck Disability Index, Short Form-36 physical component summary, and pain scales for neck and arm pain: the minimum clinically important difference and substantial clinical benefit after cervical spine fusion. Spine J. 2010;10:469-74.

9. Shao $Z X$, Yan YZ, Pan XX, et al. Factors associated with cervical spine alignment in an asymptomatic population: a preliminary analysis. World Neurosurg. 2019;122:e48-58. https://doi.org/10.1016/j.wneu.2018.09.036.

10. Knott PT, Mardjetko SM, Techy F. The use of the T1 sagittal angle in predicting overall sagittal balance of the spine. Spine J. 2010;10:994-8.

11. Gillis Christopher C, Kaszuba Megan C, Traynelis Vincent C. Cervical radiographic parameters in 1-and 2-level anterior cervical discectomy and fusion.[J]. J Neurosurg Spine. 2016;25:421-9.

12. Zhu Y, Zhongcheng A, Yingjian Z, Hao W, Dong L. Predictive formula of cervical lordosis in asymptomatic young population. J Orthop Surg Res. 2020;15(1):2. https://doi.org/10.1186/s13018-019-1526-x.

13. Lee SH, Kim KT, Seo EM, et al. The influence of thoracic inlet alignment on the craniocervical sagittal balance in asymptomatic adults[]]. J Spinal Disord Tech. 2012;25(2):E41-7.

14. Lin T, Chen P, Wang Z, Chen G, Liu W. Does cervical sagittal balance affect the preoperative Neck Disability Index in patients with cervical myelopathy? Clin Spine Surg. 2020:33(1):E21-5. https://doi.org/10.1097/BSD. 0000000000000916.
15. Poh LF, Chevillotte $T$, Leglise $A$, et al. Which parameters are relevant in sagittal balance analysis of the cervical spine? A literature review [J]. Eur Spine J. 2018;27:8-15.

16. Wu WJ, Jiang LS, Liang Y, et al. Cage subsidence does not, but cervical lordosis improvement does affect the long-term results of anterior cervical fusion with standalone cage for degenerative cervical disc disease: a retrospective study. Eur Spine J. 2012;21:1374-82.

17. Koeppen D, Piepenbrock C, Kroppenstedt $S$, et al. The influence of sagittal profile alteration and final lordosis on the clinical outcome of cervical spondylotic myelopathy. A Delta-Omega-analysis. PLoS One. 2017;12: e0174527.

18. McAviney J, Schulz D, Bock R, et al. Determining the relationship between cervical lordosis and neck complaints. J Manip Physiol Ther. 2005:28:187-93.

19. Tang JA, Scheer JK, Smith JS, et al. The impact of standing regional cervical sagittal alignment on outcomes in posterior cervical fusion surgery. Neurosurgery. 2015;76(Suppl 1):S14-21. https://doi.org/10.1227/01.neu. $0000462074.66077 .2 b$

20. Justin I, Virginie $L$, Renaud $L$, et al. The effect of aging on cervical parameters in a normative North American population [J]. Global Spine J. 2018:8:709-15.

\section{Publisher's Note}

Springer Nature remains neutral with regard to jurisdictional claims in published maps and institutional affiliations.
Ready to submit your research? Choose BMC and benefit from:

- fast, convenient online submission

- thorough peer review by experienced researchers in your field

- rapid publication on acceptance

- support for research data, including large and complex data types

- gold Open Access which fosters wider collaboration and increased citations

- maximum visibility for your research: over $100 \mathrm{M}$ website views per year

At BMC, research is always in progress.

Learn more biomedcentral.com/submission 